\title{
Mycobacterium xenopi pulmonary infections: a multicentric retrospective study of 136 cases in north-east France
}

\author{
C Andréjak, ${ }^{1} \mathrm{~F}-\mathrm{X}$ Lescure, ${ }^{2,3} \mathrm{E}$ Pukenyte, ${ }^{4} \mathrm{Y}$ Douadi, ${ }^{2} \mathrm{Y}$ Yazdanpanah, ${ }^{4} \mathrm{G}$ Laurans, ${ }^{5}$ \\ J-L Schmit, ${ }^{2}$ V Jounieaux, ${ }^{1}$ and the Xenopi Group*
}

- Table 2 and figs 3-7 are published online only at http:// thorax.bmj.com/content/vol64/ issue4

${ }^{1}$ Pneumology Department, Teaching Hospital Amiens, Amiens, France; ${ }^{2}$ Infectious Diseases Department, Teaching Hospital Amiens, Amiens, France; ${ }^{3}$ Infectious Diseases Department, APHP Teaching

Tenon Hospital, Paris, France;

${ }^{4}$ Infectious Diseases

Department, Tourcoing Hospital, Tourcoing, France; ${ }^{5}$ Bacteriology Laboratory, Teaching Hospital

Amiens, Amiens, France

Correspondence to: Dr C Andréjak, Pneumology Department, Teaching Hospital Amiens, Amiens, France; claireski2002@yahoo.fr

*The list of participants appears at the end of the paper.

Received 29 January 2008 Accepted 20 November 2008 Published Online First

2 December 2008

\section{ABSTRACT}

Background: Owing to its low incidence, the management of Mycobacterium xenopi pulmonary infections is not clearly defined. A multicentre retrospective study was performed to describe the features of the disease and to evaluate its prognosis.

Methods: All patients with M xenopi satisfying the 1997 ATS/IDSA criteria from 13 hospitals in north-east France (1983-2003) were included in the study. Clinical, radiological and bacteriological characteristics and data on the management and outcome were collected.

Results: 136 patients were included in the analysis, only 12 of whom presented with no co-morbidity. Three types of the disease were identified: (1) a classical cavitary form in patients with pre-existing pulmonary disease $(\mathrm{n}=39$, $31 \%)$; (2) a solitary nodular form in immunocompetent patients $(n=41,33 \%)$ and (3) an acute infiltrate form in immunosuppressed patients $(n=45,36 \%) .56$ patients did not receive any treatment; the other 80 patients received first-line treatment containing rifamycin (87.5\%), ethambutol (75\%), isoniazid (66.2\%), clarithromycin (30\%) or fluoroquinolones (21\%). After a follow-up of 36 months, 80 patients (69.1\%) had died; the median survival was 16 months (range 10-22). Two independent prognostic factors were found: the acute infiltrate form was associated with a bad prognosis (hazard ratio 2.6, $p=0.001$ ) and rifamycin-containing regimens provided protection (hazard ratio $0.325, p=0.006$ ). Clarithromycin-containing regimens did not improve the prognosis.

Conclusions: In contrast to recent guidelines, this study showed three different types of the disease (cavitary, nodular or diffuse infiltrate forms) with a different prognosis. In order to improve survival, all patients with $M$ xenopi infection should be treated with a rifamycincontaining regimen. The usefulness of clarithromycin remains to be evaluated.

Mycobacterium xenopi is a non-tuberculous mycobacterium responsible for lung disease, ${ }^{1}$ especially in north-east France, south-east UK and in Ontario, Canada. ${ }^{2}{ }^{3}$ According to the recent ATS/ IDSA statement, its usual feature is an apical cavitary process in patients with obstructive pulmonary disease. ${ }^{4}$ However, other features have been described. ${ }^{5} M$ xenopi infections are difficult to treat and there is no standard treatment. ${ }^{235}$ Rifampin, ethambutol and sometimes isoniazid or fluoroquinolones are usually recommended in combination with clarithromycin. ${ }^{4}$ Two randomised clinical trials have been conducted by Jenkins et al. ${ }^{67}$ In the first study, 42 patients were treated with rifampin and ethambutol with or without isoniazid, without any difference in the clinical response. ${ }^{6}$ The overall mortality rate at 5 years was $69 \%$. In the second study, Jenkins et al compared clarithromycin with a ciprofloxacin-containing regimen in 371 patients infected with non-tuberculous mycobacteria and found no difference in the 34 patients infected with $M$ xenopi.

As $M$ xenopi infection could present with different clinical and radiological patterns depending on the patient's immunological status, we conducted a multicentre retrospective study to determine the clinical and radiological characteristics of patients with $M$ xenopi infection and to evaluate the 36-month survival rate and prognostic factors.

\section{METHODS}

In 13 hospitals in north-east France (the "Xenopi Group"), the clinical files and bacteriology laboratory data were reviewed for all patients with at least one pulmonary bacteriological specimen positive for $M$ xenopi between 1 January 1983 and 31 December 2003. To be included, patients had to be aged >18 years and to fulfil the 1997 ATS diagnostic criteria for non-tuberculous mycobacterial pulmonary infection. ${ }^{8}$

\section{Definitions and recorded data}

Clinical, radiographic and microbiological data were collected for patients with documented $M$ xenopi infection (defined according to the 1997 ATS criteria). Radiographic abnormalities (nodular, infiltrative or cavitary) were analysed by chest radiography and/or CT scanning. Treatments were identified as first, second and third drug combinations, taken for at least 1 month. Outcomes were defined as cure, relapse or death. Patients were considered to be cured when there was no specimen culture positive for $M$ xenopi during the last 3 months of treatment and 3 years after discontinuation of treatment. However, as such bacteriological follow-up was not systematically performed, patients were also considered to be cured when no relapse was observed during the 3 years after finishing treatment. For patients who died, the cause of death was noted. Survival at 36 months was chosen as the primary end point in the survival analysis. Prognostic factors among the recorded clinical, radiographic and microbiological characteristics and treatment were sought. We also evaluated the specific role of each molecule in the 
Table 1 Patient characteristics for the whole population and according to the radiological form detected on admission

\begin{tabular}{|c|c|c|c|c|}
\hline & $\begin{array}{l}\text { Whole } \\
\text { population } \\
\text { (n=136) }\end{array}$ & $\begin{array}{l}\text { Cavitary form } \\
(\mathrm{n}=39)\end{array}$ & $\begin{array}{l}\text { Nodular form } \\
(n=41)\end{array}$ & $\begin{array}{l}\text { Infiltrate form } \\
(n=45)\end{array}$ \\
\hline \multicolumn{5}{|l|}{ Age (years) } \\
\hline Mean (SE) & $53(16)$ & $52(17)$ & $51(16)$ & $48(19)$ \\
\hline Median (range) & $53(20-91)$ & $54(30-77)$ & $52(20-79)$ & $40(26-81)$ \\
\hline Gender (M/F) & $104 / 32$ & $28 / 11$ & $32 / 9$ & $36 / 9$ \\
\hline No history, n (\%) & $12(9 \%)$ & $2(5 \%) \dagger$ & $9(22 \%) \dagger+$ & $0 \%$ \\
\hline Systemic immunosuppression, n (\%) & $71(52.2 \%)$ & $16(41 \%)^{*}$ & $16(39 \%) \%$ & $32(71 \%) *^{*}$ \\
\hline Neoplasm, n (\%) & $27(20 \%)$ & $8(21 \%)$ & $9(22 \%)$ & $5(11 \%)$ \\
\hline HIV, n (\%) & $38(28 \%)$ & $4(10 \%)^{*}$ & $6(14.5 \%) \ddagger$ & $26(58 \%) *^{*}$ \\
\hline Local immunosuppression, n (\%) & $76(56 \%)$ & $30(77 \%)^{*}$ & $23(56 \%)$ & $16(36 \%)^{*}$ \\
\hline COPD, n (\%) & $59(43 \%)$ & $22(56 \%)^{*}$ & $20(49 \%)$ & $12(27 \%)^{*}$ \\
\hline Pulmonary tuberculosis, n (\%) & $35(26 \%)$ & $13(33 \%)$ & $10(24 \%)$ & $9(20 \%)$ \\
\hline Bronchiectasis, n (\%) & $12(9 \%)$ & $2(5 \%)$ & $6(14.5 \%)$ & $3(7 \%)$ \\
\hline Alteration of general state, $\mathrm{n}(\%)$ & $121(89 \%)$ & $36(92 \%)$ & $35(85 \%)$ & $40(89 \%)$ \\
\hline Respiratory symptoms, n (\%) & $130(96 \%)$ & $36(94 \%)$ & $40(97 \%)$ & $43(96 \%)$ \\
\hline Cough, n (\%) & $107(79 \%)$ & $31(79 \%)$ & $33(80.5 \%)$ & $37(82 \%)$ \\
\hline Sputum, n (\%) & $86(63 \%)$ & $24(62 \%)$ & $28(68 \%)$ & $26(58 \%)$ \\
\hline Haemoptysis, n (\%) & $15(11 \%)$ & $7(18 \%)$ & $4(10 \%)$ & $3(7 \%)$ \\
\hline Extrapulmonary signs, n (\%) & $22(16 \%)$ & $4(10 \%)$ & $3(7 \%) \dagger^{*}$ & $13(29 \%) *^{*}$ \\
\hline Pathological pulmonary auscultation, n (\%) & $131(96 \%)$ & $23(59 \%)$ & $25(61 \%)$ & $27(60 \%)$ \\
\hline Sweating, n (\%) & $8(6 \%)$ & $3(8 \%)$ & $1(2.5 \%)$ & $4(9 \%)$ \\
\hline Diagnosis by sputum culture only, $\mathrm{n}(\%)$ & $52(39 \%)$ & $8 / 24(33 \%)$ & $11 / 21(52 \%)$ & $6 / 20(30 \%)$ \\
\hline Autopsy diagnosis, n (\%) & $6(4 \%)$ & $1(3 \%)^{*}$ & $0 \ddagger$ & $5 / 41(12 \%) \div *$ \\
\hline Aspergillus co-infection, $\mathrm{n}(\%)$ & $14(10 \%)$ & $5(13 \%)$ & $8(19.5 \%)+$ & $1(2 \%) *$ \\
\hline
\end{tabular}

*Statistically significant difference between cavitary and infiltrate forms $(p<0.03)$.

$\dagger$ Statistically significant difference between cavitary and nodular forms $(p<0.03)$.

$¥$ Statistically significant difference between infiltrate and nodular forms $(p<0.03)$.

Description of patient characteristics according to the radiological form detected on admission is based on 125 patients (130 chest radiographs were available and 125/130 were abnormal).

COPD, chronic obstructive pulmonary disease.

survival analysis. The data were checked for a possible period effect (before and after 1997) because highly active antiretroviral therapy (HAART), available since 1996, has improved the prognosis of HIV-infected patients.

\section{Statistical analysis}

Statistical analysis was performed with SPSS 12.0 software. Descriptive analysis of continuous quantitative variables is expressed as mean (SD) and qualitative variables as frequency (\%). Univariate comparative analysis was performed with the Fisher exact text for qualitative variables and a Student $t$ test or a Kruskal-Wallis non-parametric test for continuous variables. Univariate survival analysis was performed with a Kaplan-Meier non-parametric test and multivariate analysis with a Cox model. A $p$ value $<0.03$ was considered to be statistically significant and was chosen according to the Bonferroni method in order to integrate the interim analysis. ${ }^{9}$ Percentages are expressed in relation to the total population unless otherwise specified.

\section{RESULTS}

During the period from 1983 to 2003, 180 patients with at least one positive specimen for $M$ xenopi were eligible. Forty-four patients (24\%) were considered to be colonised by $M$ xenopi and were excluded. The remaining 136 patients (104 men, 32 women, mean age 53 (16) years, median 53 years (range 20-91)) met the criteria required by the 1997 ATS (and also the 2007 ATS/IDSA criteria) and were included in the study. ${ }^{4}{ }^{8}$

\section{Population}

One hundred and twenty-four patients (91\%) had co-morbidities - a history of systemic immunosuppression in $52.2 \%$ and/ or local pulmonary immunosuppression in 56\%. The characteristics of the patients are shown in table 1.

\section{Imaging}

A chest radiograph was available for 130 patients and was found to be abnormal in 125 cases (96\%). A CT scan, performed in 71 patients, was always abnormal. Unilateral or bilateral apical shadows (nodule, cavitary and infiltrate) were observed in 55 patients $(55 / 125,44 \%)$ and were more frequently located in the right upper lobe (53/125, $42 \%$; fig 1$)$.

\section{Microbiology}

A median of 3 (range 1-11) specimens were obtained with a median of 3 (range 1-11) positive specimens: sputum culture $(n=78,57.4 \%)$, bronchoalveolar lavage fluid $(n=57,41.9 \%)$, bronchial aspirate $(n=38,27.9 \%)$, gastric fluid $(n=20,14.7 \%)$, surgical biopsy $(n=8,5.8 \%)$, bronchial biopsy $(n=4,2.9 \%)$ and autopsy $(n=6,4.4 \%)$. Eighty-three patients had one or more smear positive. The median time to diagnosis was 2 months (range 1-60). Antibiotic susceptibility testing was performed in 58 cases $(44 \%)$. The strains were reported as resistant to isoniazid in $75 \%$, to rifampin in $40 \%$, to ethambutol in $24 \%$ and to clarithromycin in $2.5 \%$. Co-infections were found in 23 patients (Aspergillus fumigatus in 14 and Pneumocystis jiroveci in 9). 


\section{A}
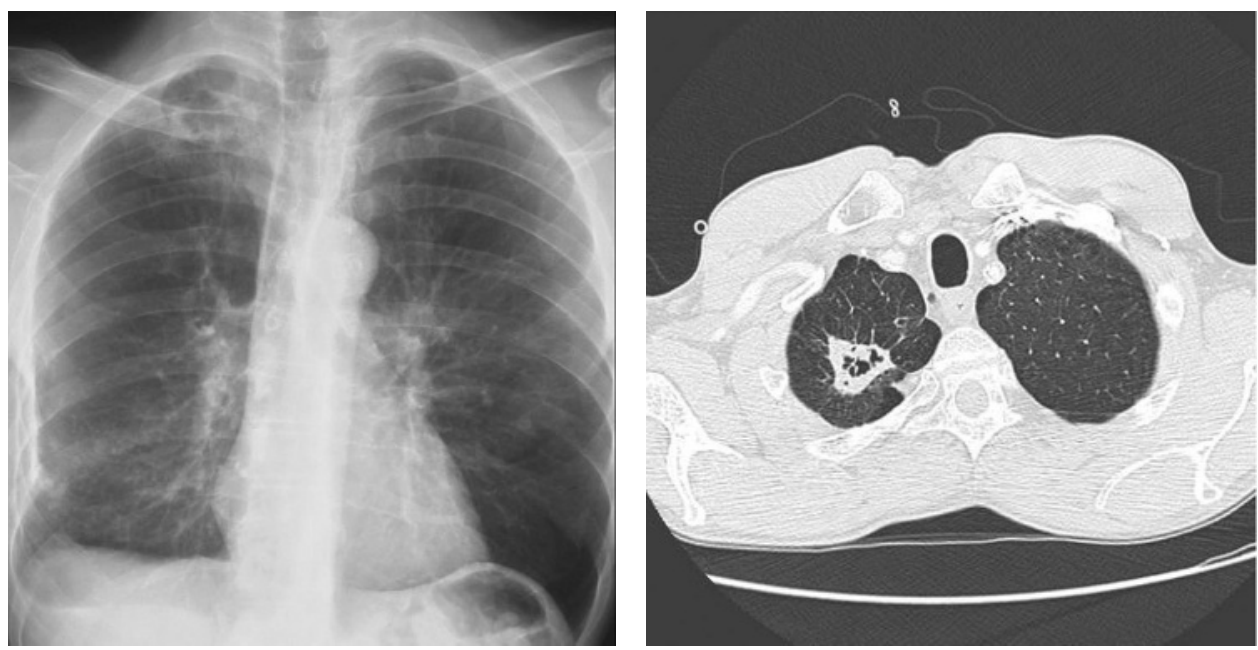

B
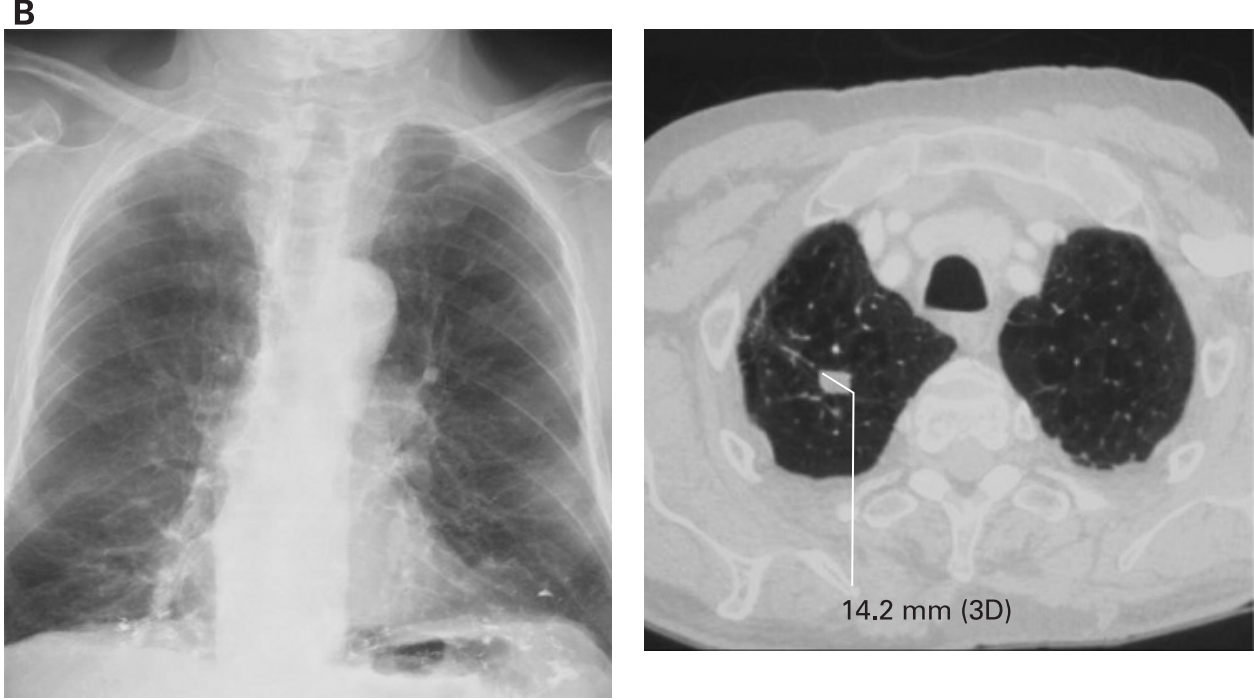

C
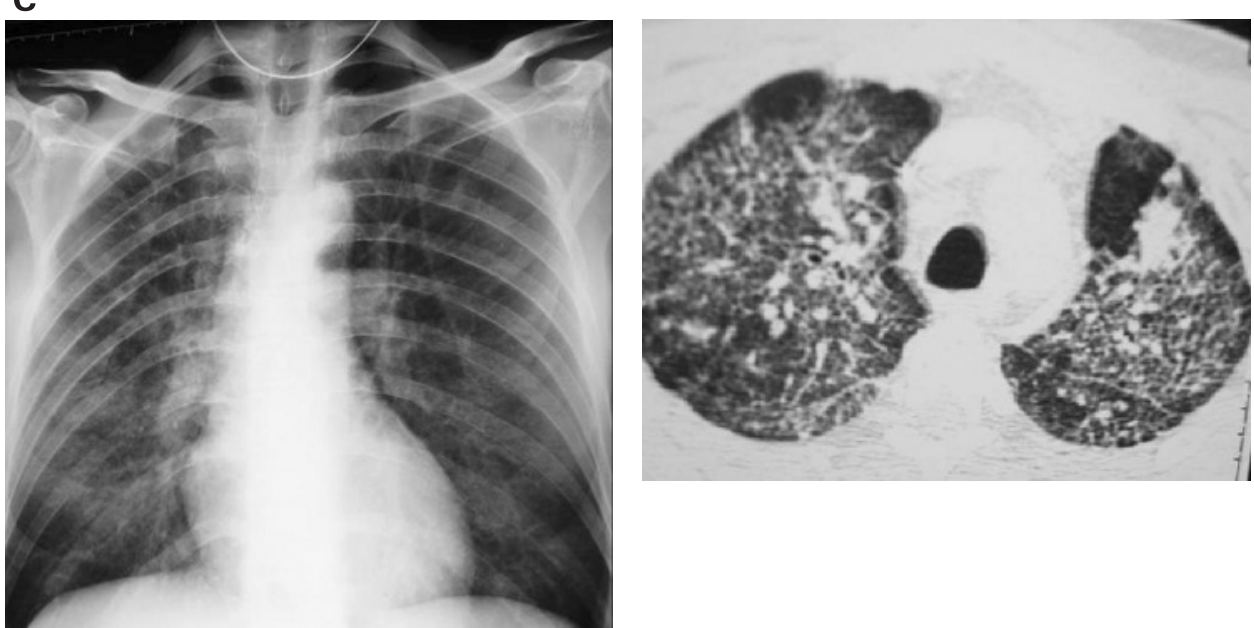

Figure 1 Chest radiograph and CT scan of (A) cavitary form, (B) nodular form and (C) infiltrate form.

\section{Typology of $M$ xenopi pulmonary infection}

The typology of $M$ xenopi pulmonary infection was established for the 125 patients with an abnormal shadow on the chest radiograph. Three radiological patterns were distinguished: the cavitary form $(39 / 125,31 \%)$, the nodular form $(41 / 125,33 \%)$ and the infiltrate form $(45 / 125,36 \%$; fig 1 and table 1$)$.

In 39 patients the radiographic appearance was a cavitary process. An underlying lung disease was significantly more frequent in these patients than in other patients $(77 \%$ (30/39) vs 


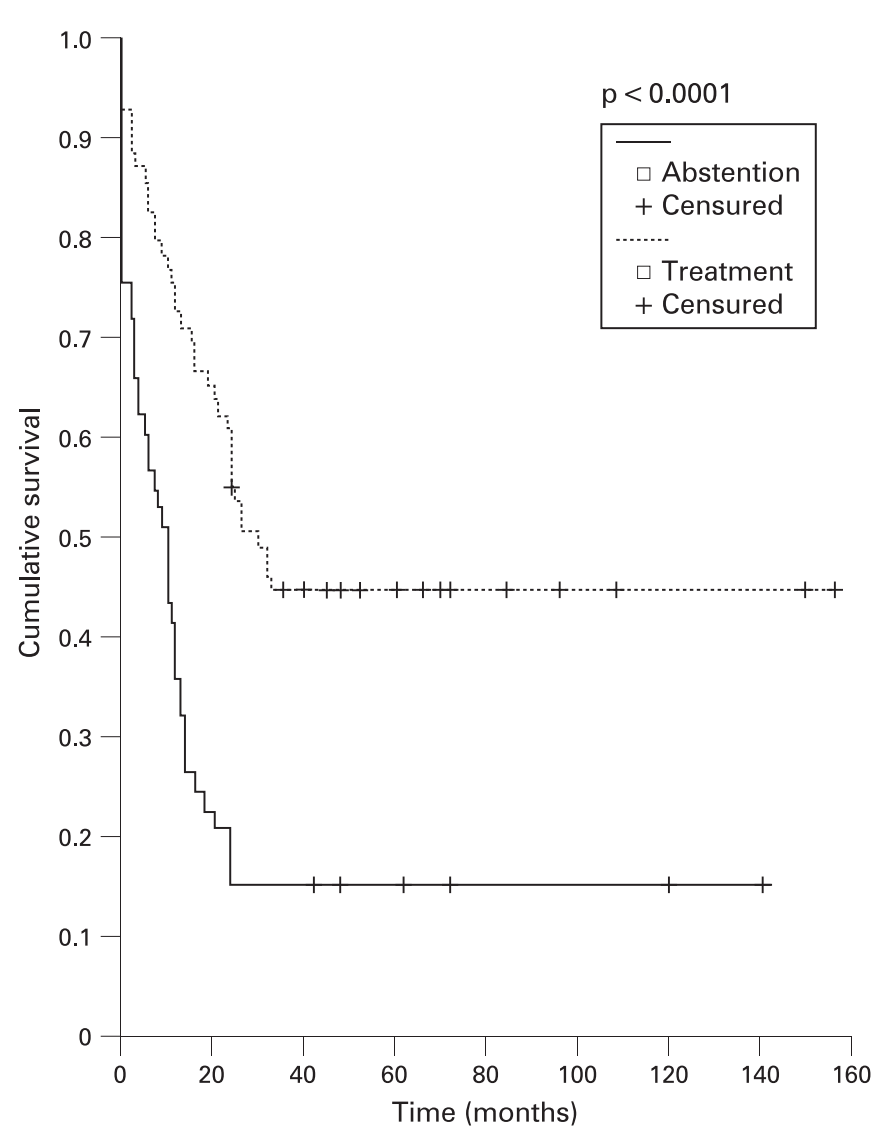

Figure 2 Cumulative survival according to whether or not the patient was treated. Treatment is defined as the use of a combination of antibiotics for at least 1 month, or surgical management, or the combination of medical and surgical treatment.

$45 \%(39 / 86), p=0.009)$. For these patients, all specimens were positive.

Forty-one patients presented with a nodular radiological form. Most of them had no co-morbidity compared with patients with other patterns $(22 \%(9 / 41)$ vs $2 \%(2 / 84)$, $p=0.001)$. Five cases $(12 \%)$ in this subgroup required surgical biopsy for diagnosis.

The remaining 45 patients showed an infiltrate radiological form. These patients were significantly younger than the other patients (48 years vs 54 years, $p=0.031$ ) and associated comorbidities were significantly more frequent $(100 \%(45 / 45)$ vs $86 \%(69 / 80), p=0.015)$, especially HIV-associated systemic immunosuppression (58\% (26/45) vs $13 \%$ (10/80), p<0.001), with a lower incidence of underlying pulmonary disease $(36 \%$ $(16 / 45)$ vs $66 \%(53 / 80), \quad p=0.002)$ in this subgroup. Bronchoalveolar lavage was required more frequently in this subgroup for diagnosis (61\% vs $32 \%, p=0.002)$.

\section{Treatment regimens}

Fifty-six patients (41.2\%) did not receive any drug and 21 patients died before the bacteriological diagnosis was made. Surgical resection was proposed in 6 patients $(8 \%)$. Physicians decided to withhold treatment in 35 patients, especially in those with the nodular form $(51.2 \%$ vs $30.9 \%$ in the other patterns, $\mathrm{p}=0.03$ ). Patients with a cavitary process were treated more frequently than the other patients ( $83.3 \%$ vs $54.7 \%, p=0.004$; see fig 3 in online supplement). Patients with a positive smear were treated more frequently $(75.9 \%$ vs $32.1 \%$, p $<0.001)$. Firstline drug combinations that contained an average of four antibiotics consisted of a combination of a rifamycin (70/80, $88 \%$ : rifampicin, $\mathrm{n}=58$; rifabutin, $\mathrm{n}=12$ ) and/or ethambutol $(60 / 80,75 \%)$ and/or isoniazid $(53 / 80,66 \%)$ and/or clarithromycin $(24 / 80,30 \%)$ and/or a fluoroquinolone (17/80, $21 \%$ : ofloxacin, $n=14$; ciprofloxacin, $n=3$ ). The median duration of the first-line drug combination was 5 months (range 1-72). Twenty-eight of these 80 patients received a second drug combination containing clarithromycin $(23 / 28,82.1 \%)$ and/or a fluoroquinolone $(17 / 28,60.7 \%)$ and/or a rifamycin $(16 / 28,57 \%)$ and/or ethambutol $(13 / 28,46.4 \%)$ and/or isoniazid (5/28, $18 \%)$, with a median duration of 5 months (range 1-12) (see fig 4 in online supplement). Only 13 patients (9.5\%) received a third drug combination. The mean total duration of treatment was 9 months (range 2-25) with 34 adverse effects that required changes in treatment.

\section{Outcome}

Fourteen of the 136 patients were lost to follow-up. Survival analysis was therefore based on the remaining 122 patients. Twenty-six patients achieved a "clinical" cure and 7 fulfilled the criteria for a bacteriological cure. Twenty-one relapses were diagnosed after a median period of 5 months (range 1-40), 14 of whom were treated. The only significant predisposing factor to relapse was a treatment duration $<6$ months (85\% vs $36 \%$, $\mathrm{p}=0.03$ ).

The median survival of these 122 patients was 16 months (range 10-22). Twenty-one patients died before the bacteriological diagnosis and 26 before the planned end of treatment. When a follow-up of 36 months was applied, 80 patients (69.1\%) had died at this end point with a median time to death of 9 months (range 1-120). Deaths were attributed to $M$ xenopi infection in 49 cases $(61.2 \%)$, to the underlying disease in 24 $(30 \%)$ and to another cause in 7 cases $(8.7 \%)$.

\section{Prognostic factors (Kaplan-Meier univariate analysis)}

Prognostic factors according to the Kaplan-Meier univariate analysis are shown in table 2 in the online supplement.

\section{Clinical characteristics}

Immunosuppression was found to be a poor prognostic factor (11 months vs 30 months, $p=0.002$; hazard ratio (HR) 2.8 ( $95 \%$ confidence interval (CI) 1.3 to 6.2 ), $p=0.007$ ). We found a period effect on survival (12 months before 1997 and 20 months after 1997 (HR 1.5 (95\% CI 1.0 to 2.3), p=0.05)) and, when patients were stratified according to HIV status, median survival improved after 1997 only in HIV-infected patients $(p=0.002)$.

\section{Clinical and radiological patterns}

When survival was analysed according to the three radiological patterns, a significantly longer survival was observed in patients with the nodular form (24 months vs 13 months, $p=0.039$; HR 0.42 (95\% CI 0.18 to 0.96$)$ ), whereas the worst prognosis was observed with the diffuse infiltrate pattern ( 9 months vs 25 months, $\mathrm{p}<0.001$; HR 3.48 (95\% CI 1.29 to 9.40)).

\section{Microbiology data}

For bacteriological results, no difference in survival was observed between positive or negative smears $(p=0.2)$ and between susceptible and resistant strains either to rifampicin, ethambutol or clarithromycin. 


\section{Treatment regimens}

The absence of treatment was a factor for a poor prognosis, with a median survival of 10 months in untreated patients and 32 months in treated patients (HR 3.04 (95\% CI 1.94 to 4.74), $\mathrm{p}<0.001$; fig 2). Rifamycin-containing regimens were associated with a significant improvement in the median survival $(p<0.001$ in first-line drug combinations and $p=0.03$ in later drug combinations; see fig 5 in online supplement). Similar findings were observed with rifamycin+ethambutol-containing regimens $(p=0.001$ and $p=0.01$, respectively; see fig 6 in online supplement). Clarithromycin, either as first-line $(p=0.18)$ or any drug combination, did not influence the prognosis ( $p=0.57$; see fig 7 in online supplement). For ethambutol, the significant improvement in survival observed in first-line drug regimens $(p=0.01)$ was not found for other regimens $(p=0.88)$. Similar findings were observed for isoniazid ( $p=0.013$ and $p=0.79$ for first-line and later combinations). No significant difference in survival was observed with fluoroquinolones. First-line surgery was associated with an improvement in survival $(p=0.04)$. An interaction study with rifamycin-ethambutol, rifamycin-clarithromycin and rifamycinisoniazid did not demonstrate any significant synergistic activity. A treatment duration of $\leqslant 6$ months was a poor prognostic factor $(p=0.008)$.

\section{Prognostic factors (multivariate analysis according to the Cox model)}

The following variables were entered into the model: systemic immunosuppression, infiltrate radiological pattern, rifamycincontaining regimen, ethambutol-containing regimen and clarithromycin-containing regimen. Two independent prognostic factors were found: the presence of the infiltrate radiological pattern was associated with a bad prognosis (HR 2.60 (95\% CI 1.44 to 4.45$), p=0.001$ ) while combination therapy with a rifamycin-containing regimen was found to be a protective factor (HR 0.33 (95\% CI 0.15 to 0.72 ), $p=0.006$ ). The presence of systemic immunosuppression tended to be associated with a poor prognosis (HR 1.87 (95\% CI 1.09 to 3.27 ), $p=0.039$ ).

\section{DISCUSSION}

Despite the fact that recent guidelines have considered $M$ xenopi infection to be a single disease (cavitary form), ${ }^{4}$ our results support a new approach based on three clinical and radiological features: nodular, cavitary and infiltrate forms.

The cavitary form, which accounted for $31 \%$ of our cases, corresponds to the "classical" type with a clinical presentation similar to that of tuberculosis and a diagnosis easily made from sputum smears. ${ }^{4}{ }^{10-12}$ It is mainly observed in patients with an underlying pulmonary disease (such as chronic obstructive pulmonary disease or bronchectasis). The nodular form, which is often observed in immunocompetent adults, is the least aggressive form and often has a delayed diagnosis. The main danger in this form is to consider a positive sample as a contaminated specimen and then not to repeat the samples. The diffuse infiltrate form, which is mainly observed in young immunosuppressed patients (mainly by HIV infection), is the most serious form of $M$ xenopi infection. More aggressive methods are usually required to assess the diagnosis (repeated bronchoalveolar lavage and/or transbronchial biopsies).

In our patients, $M$ xenopi infection appeared to be a disease with a 3-year mortality rate of $69.1 \%$ and a mean time to death of 9 months.
Like other authors, ${ }^{13-16}$ we have questioned the value of treatment. The only independent modifiable prognostic factor we found for the whole group, whatever the feature (nodular, cavitary or infiltrative form), was active treatment, particularly rifamycin-containing regimens. Owing to the lack of randomised trials and the lack of agreement in guidelines, the choice of drugs remains difficult. Treatment could be based on antibiotic susceptibility testing but many $M$ xenopi strains appear to be resistant to rifampicin, isoniazid and ethambutol in vitro. ${ }^{17}{ }^{18}$ As in our study, an absence of in vitro/in vivo correlation has been emphasised in the literature. ${ }^{691920}$ In contrast with in vitro data and according to our results, treatment should contain a rifamycin, which is also recommended by the American Thoracic Society and the British Thoracic Society. ${ }^{4} 821$ Clarithromycin, which shows excellent in vitro activity, ${ }^{17}$ did not appear to improve survival in our study, whether administered as first-line treatment or later. With regard to the usefulness of clarithromycin, the only in vivo study was conducted in mice ${ }^{18}$ and other publications are isolated case reports. ${ }^{22}$ Juffermans et al reported the almost complete absence of in vitro resistance to clarithromycin but failed to find any improvement in outcome with this drug. ${ }^{23}$ Arguments in favour of the in vivo efficacy of clarithromycin on $M$ xenopi are based on the in vivo efficacy of clarithromycin on Mycobacterium avium intracellulare complex. ${ }^{24} 25$ On the basis of a single unpublished abstract, ${ }^{26}$ clarithromycin has been recommended since $1997 . .^{4}$ Since this date, only one randomised study has been published which did not observe any difference in mortality between the clarithromicyn and ciprofloxacin treatment arms. ${ }^{7}$ This result is difficult to interpret due to the small number of patients (17 in each group). Ethambutol appears to be useful as it promotes the in vivo penetration of other antibiotics such as rifamycin into mycobacteria. ${ }^{17} 27$ Ethambutol was found to be a good prognostic factor, but not an independent one, probably because it is usually associated with a rifamycin. Surgery, which in our study was associated with a significantly prolonged survival, was performed for diagnostic purpose in patients whereas, in the literature, it has been reserved for cases of chemotherapy failure in patients with localised lesions. ${ }^{2} 82829$

In conclusion, $M$ xenopi infection remains difficult to diagnose and requires microbiological assessment whatever the radiological features. This infection should no longer be considered as a uniform disease as we were able to distinguish three radiological forms. The cavitary form usually occurred in patients with underlying pulmonary disease, the nodular form in immunocompetent patients and the diffuse infiltrate form usually affected young immunosuppressed patients. The prognosis of $M$ xenopi infection remains extremely poor, and rifamycincontaining regimens must be prescribed in all patients except those in which it is contraindicated. As yet there is no evidence of any benefit of adding clarithromycin to the treatment regimen, but a controlled study is needed to confirm this.

Acknowledgements: The authors acknowledge the following members of the Xenopi Group: Arras (Dr Bervar, Noulard); Besançon (Professor Hoen and Professor Plesiat); Compiègne (Dr Merrien); Creil (Drs Lamarck, Lemaitre and Merour); Dijon (Professor Chavanet and Professor Kazmierczak); Lens (Dr Bure and Dr Canonne); Lille (Professor Wallaert and Dr Wallet); Nancy (Professors Martinet et May, Dr Dailloux); Reims (Drs Deslee, Strady et Vallerand, Professor De Champs de Saint Léger); Saint Quentin (Drs Albertini and Dayen); Strasbourg (Professors Martin, Monteil, Pauli and Weitzenblum); Tourcoing (PrYazdanpanah and Dr Dhennain). They also acknowledge the InterCISIH Nord-Est for this collaboration and Professor Jacques Grosset for his advice.

Funding: None.

Competing interests: None. 


\section{REFERENCES}

1. Schwabacher H. A strain of mycobacterium isolated from skin lesions of a coldblooded animal, Xenopus laevis and its relation to atypical acid fast bacilli occurring in man. J Hyg (Lond) 1959:57:56-67.

2. British Thoracic Society. Management of opportunist mycobacterial infections: Joint Tuberculosis Committee guidelines 1999. Thorax 2000;55:210-8.

3. Andréjak C, Lescure FX, Douadi Y, et al. Non tuberculous mycobacteria pulmonary infection: management and follow-up of 31 infected patients. J Infect 2007;55:34-40.

4. Griffith DE, Aksamit T, Brown-Eliott BA, et al. An official ATS/IDSA statement: diagnosis, treatment, and prevention of nontuberculous mycobacterial diseases. Am J Respir Crit Care Med 2007;175:367-416.

5. El-Helou P, Rachlis A, Fong I, et al. Mycobacterium xenopi infections in patients with human immunodeficiency virus infection. Clin Infect Dis 1997;25:206-10.

6. Jenkins PA, Campbell IA, Research Committee of the British Thoracic Society. Pulmonary disease caused by Mycobacterium xenopi: five year follow-up of patients receiving standardised treatment. Respir Med 2003;97:439-44.

7. Jenkins PA, Campbell IA, Banks J, et al. Clarithromycin vs ciprofloxacin as adjuncts to rifampicin and ethambutol in the treatment of opportunist mycobacterial pulmonary diseases and an assessment of Mycobacterium vaccae immunotherapy. Thorax 2008;63:627-34.

8. American Thoracic Society. Diagnosis and treatment of disease caused by non tuberculous mycobacteria. Am J Respir Crit Care Med 1997:156:S1-25.

9. Andréjak C, Lescure FX, Douadi $Y$, et al. Treatment, survival and prognostic factors in 89 patients infected with Mycobacterium xenopi. Proc Am Thorac Soc 2006;3:A747.

10. Banks J, Hunter AM, Campbell IA, et al. Pulmonary infection with Mycobacterium xenopi: review of treatment and response. Thorax 1984;39:376-82.

11. Smith MJ, Citron KM. Clinical review of pulmonary disease caused by Mycobacterium xenopi. Thorax 1983;38:373-7

12. Costrini AM, Mahler DA, Gross WM, et al. Clinical and roentgenographic features of nosocomial pulmonary disease due to Mycobacterium xenopi. Am Rev Respir Dis 1981;123:104-9

13. El-Sohl AA, Nopper J, Abdul-Khoudoud MR, et al. Clinical and radiographic manifestations of uncommon pulmonary nontuberculous mycobacterial disease in AIDS patients. Chest 1998:114:138-45.

14. Gazzola L, Cesari M, Salerno F, et al. Clinical and therapeutic management of pulmonary Mycobacterium xenopi infection in HIV-positive patients. Clin Infect Dis 2004:38:1642-4.
15. Kerbiriou L, Ustinaowski A, Johnson MA, et al. Human immunodeficiency virus type 1 related pulmonary Mycobacterium xenopi infection: a need to treat? Clin Infect Dis 2003;37:1250-4.

16. Bachmeyer C, Blum L, Benchaa B, et al. Mycobacterium xenopi pulmonary infection in an HIV infected patient under highly active antiretroviral treatment. Thorax 2001;56:978-9.

17. Dauendorffer JN, Laurain $\mathrm{L}$, Weber $\mathrm{M}$, et al. In vitro sensitivity of Mycobacterium xenopi to five antibiotics. Pathol Biol 2002;50:591-4.

18. Lounis $\mathbf{N}$, truffot-Pernot $\mathbf{C}$, Bentoucha $A$, et al. Efficacies of clarithromycine regimens against Mycobacterium xenopi in mice. Antimicrob Agents Chemother 2001:45:3229-30.

19. Manfredi R, Nanetti A, Tadolini M, et al. Role of Mycobacterium xenopi disease in patients with HIV infection at the time of highly active antiretroviral therapy (HAART). Comparison with the pre-HAART period. Tuberculosis 2003;83:319-28.

20. Baugnée PE, Pouthier F, Delaunois L. Mycobacteriose pulmonaire à Mycobacterium xenopi : sensibilité " in vitro» aux antituberculeux classiques et évolution clinique. Acta Clin Belg 1996;51:19-27.

21. Wallace RJ, O'Brien R, Glassroth J, et al. Diagnosis and treatment of disease caused by non tuberculous mycobacteria. American Thoracic Society. Am Rev Respir Dis 1990;142:940-53

22. Schmitt H, Schnitzler N, Riehl J, et al. Successful treatment of pulmonary Mycobacterium xenopi infection in a natural killer cell deficient patient with clarithromycin, rifabutin, and sparfloxacin. Clin Infect Dis 1999;29:120-4.

23. Juffermans NP, Verbon A, Danner SA, et al. Mycobacterium xenopi in HIV-infected patients: an emerging pathogen. AIDS 1998;12:1661-6.

24. Dautzenberg B, Saint Marc T, Meyohas MC, et al. Clarithromycin and other antimicrobial agents in the treatment of disseminated Mycobacterium avium infections in patients with acquired immunodeficiency syndrome. Arch Intern Med 1993:153:368-72.

25. Wallace RJ, Brown BA, Griffith DE, et al. Initial clarithromycin monotherapy for Mycobacterium avium intracellulare complex lung disease. Am J Respir Crit Care Med 1994; 149:1335-41.

26. Dautzenberg B, Papillon $\mathrm{F}$, Lepitre $\mathrm{M}$, et al. Mycobacterium xenopi infections treated with clarithromycin-containing regimens. Annual Meeting, $33^{\text {rd }}$ Interscience Conference on Antimicrobial Agents and Chemotherapy; 1993, abstract 1125.

27. Banks J, Jenkins PA. Combined versus single antituberculosis drugs on the in vitro sensitivity patterns of non-tuberculous mycobacteria. Thorax 1987;42:838-42.

28. Parrot RG, Grosset JH. Post-surgical outcome of 57 patients with Mycobacterium xenopi pulmonary infection. Tubercle 1988;69:47-55.

29. Lang-Lazdunski L, Offredo C, LePimpec-Barthes F. Pulmonary resection for Mycobacterium xenopi pulmonary infection. Ann Thorac Surg 2001:72:1877-82.

\section{Lung alert}

\section{Risk of asthma, passive smoking and genetics}

There is a known association between genetic variants on chromosome 17q21 and the development of asthma. This study investigated whether specific single nucleotide polymorphisms (SNPs) on 17q21 were linked to specific phenotypes of early-onset asthma and early-onset smoking-exposed asthma.

Individuals with asthma and their first-degree relatives were selected from seven French clinical centres. The phenotype of their asthma was determined by questionnaire. 1511 subjects took part from 372 families and 36 SNPs were genotyped. An association between an SNP and asthma was assessed using the Linkage and Association Modelling in Pedigrees program which uses a likelihood ratio test. SNPs were then further tested for an association with the specific phenotypes.

Eleven SNPs were significantly associated with asthma, three of which were found to be highly significantly associated with early-onset asthma (ie, onset $<4$ years of age). No associations could be shown with late-onset asthma. Six SNPs had a highly significant association with tobacco exposure and early-onset asthma (the most strongly associated SNP when carried homozygously carried an increase in risk by a factor of 2.9).

Although this study relied on participant recall of exposure to tobacco smoke and age of onset of asthma, the authors identified several specific genetic variables that predispose an individual to developing a specific phenotype of asthma. This adds weight to the argument that asthma actually encompasses several different pathological processes corresponding to different clinical pictures. This has implications in disease progression and management of patients.

- Bouzigon E, Corda $\mathrm{E}$, Aschard $\mathrm{H}$, et al. Effect of 17q21 variants and smoking exposure in early-onset asthma. N Engl J Med 2008;359:1985-94

\section{T J Whitfield}

Correspondence to: Dr T J Whitfield, CMT1, St James University Hospital, Leeds, UK; tomwhitfield@doctors.org.uk 